\title{
ANALISA PENGARUH KUALITAS PELAYANAN, HARGA, DAN PROMOSI TERHADAP KEPUASAN PELANGGAN PADA PERUSAHAAN PT. GARUDA INDONESIA
}

\author{
Lucia Lanny \\ Program Studi Magister Manajemen Universitas Tarumanagara \\ lucialanny@ymail.com
}

\begin{abstract}
This research includes descriptive research type of research that aims to explain the relationship between the variables studied. This research is categorized as cross sectional which will be done starting from May 2018 to get the data needed in writing this thesis, researcher conduct research to Garuda customer which located in Indonesia. Primary data is data collected by the researchers themselves from the object of research. Primary data in question through questionnaires given / distributed to Garuda's customers as respondents. Secondary data collection is relatively easy, but has advantages and disadvantages. Researcher obtain secondary data from PT company profile. GARUDA, journals, books, internet and other reading materials related to the factors to be studied. In this study, the variables used and classified into independent variables (independent variables) are service quality (x1), price (x2) and promotion (x3) and dependent variable (non-free variable) ie customer satisfaction (y) .2. It was found that the variable of service quality, price and promotion have contribution or ability to explain the variance of the purchase decision variable by $48,3 \%$ while for the rest equal to $51,7 \%$ explained by other variable not examined here.
\end{abstract}

Keywords: Kepuasan Pelanggan, Kualitas Pelayanan, Harga, Garuda Indonesia

\section{Pendahuluan}

Beberapa dasawarsa lalu, untuk berpergian antar pulau, transportasi utama masyarakat Indonesia adalah kapal laut. Hal ini dapat dipahami, mengingat rendahnya kondisi ekonomi masyarakat indonesiapada saat itu, sehingga tidak mampu untuk membeli tiket pesawat yang harganya jauh lebih tinggi jika dibandingkan dengan kapal laut. Hanya orang-orang yang memiliki uang yang lebih atau pejabat Negara yang mampu menggunakan pesawa terbang. Mahalnya menggunakan pesawat terbang dikarenakan mahalnya biaya perawatan dan biaya operasi pesawat, serta betapa kompleksnya proses sebuah pesawat untuk terbang dari suatu bandara ke bandara lain. Seiring berkembangnya zaman, satu dasarwasa belakangan, terutama saat ini, jasa penerbangan melaju pesat. Hampir seluruh lapisan masyarakat mampu berpergian dengan menggunakan pesawat terbang. sehingga tidak heran, jumlah penumpang pesawat dalam beberapa tahun belakangan terus mengalami peningkatan baik penerbangan dalam negeri maupun penerbangan luar negeri. PT. Garuda Indonesia meruapakan satusatunya penerbangan nasional di Indonesia yang menggunakan konsen Full Service Airlines. Garuda Indonesia sudah memiliki standard internasional dan tetap dengan memberikan layanan penuh bagi para konsumennya, seperti dengan memberikan promosi point reward konsumen, pelayanan makanan di dalam pesawat, dan juga perasaan aman dan nyaman. Garuda Indonesia tetap bertahan dengan penerbangan dan harga tiket yang normal. Atas dasar latar belakang tersebut, maka dalam penelitian ini peneliti mengambil judul " Analisis Pengaruh Kualitas Pelayanan, Harga dan Promosi terhadap Kepuasan Pelanggan pada perusahaan PT. Garuda Indonesia” 


\section{Hipotesis}

H1 = Diduga ada pengaruh signifikan antara kualitas pelayanan terhadap kepuasan pelanggan $\mathrm{H} 2$ = Diduga ada pengaruh signifikan antara harga terhadap kepuasan pelanggan H3 = Diduga ada pengaruh signifikan antara promosi terhadap kepuasan pelanggan H4 = Diduga ada pengaruh signifikan antara kualitas pelayanan, harga, dan promosi terhadap kepuasan pelanggan.

\section{Tinjauan Pustaka}

Menurut Kotler (2000:52), kepuasan adalah tingkat perasaan seseorang setelah membandingkan kinerja atau hasil yang dia rasakan dibandingkan dengan harapannya. Sedangkan menurut Tse dan Wilton (1988) kepuasan atau ketidakpuasan pelanggan adalah respon pelanggan terhadap evaluasi ketidaksesuaian (disconfirmation) yang dirasakan antara harapan sebelumnya dan kinerja aktual produkyang dirasakan setelah pemakaiannya (Tse dan Wilton, 1988 via Lupiyoado, 2004:349).

Kualitas sangat beraneka ragam dan mengandung banyak makna. Kualitas adalah sebuah kata yang bagi penyedia jasa merupakan sesuatu yang harus dikerjakan dengan baik. Goetsch dan Davis (1994) dalam buku Tjiptono (1996:51) mendefinisikan "kualitas merupakan suatu kondisi dinamis yang berhubungan dengan produk, jas, manusia, proses dan lingkungan yang memenuhi atau melebihi harapan. Menurut Buddy dalam buku Wahyuningsih (2002:10), "kualitas sebagai suatu strategi dasar bisnis yang menghasilkan barang dan jasa yang memenuhi kebutuhan dan kepuasan konsumen internal dan eksternal secara eksplisit dan implicit".

Harga yang merupakan satu-satunya unsur bauran pemasaran yang seringkali dijadikan sebagai bahan pertimbangan bagi konsumen dalam melakukan pembelian tidak bisa dikesampingkan oleh perusahaan. Harga menurut Kotler dan Amstrong (2001) adalah sejumlah uang yang ditukarkan untuk sebuah produk atau jasa. Lebih jauh lagi, harga adalah jumlah dari seluruh nilai yang konsumen tukarkan untuk jumlah manfaat dengan memiliki atau menggunakan suatu barang dan jasa. Harga merupakan faktor penentu yang mempengaruhi pilihan pembelian, hal ini masih menjadi kenyataan di negara-negara dunia ketiga, di kalangan kelompok-kelompok sosial yang miskin, serta pada bahanbahan pokok sehari-hari. Namun dalam dasawarsa terakhir ini, faktor-faktor lain selain harga telah beralih menjadi relatif lebih penting dalam proses pembelian.

Promosi merupakan teknik komunikasi yang secara penggunaannya atau penyampaiannya dengan menggunakan media seperti: pers, televisi, radio, papan nama, poster dan lain-lain, yang tujuannya untuk menarik minat konsumen terhadap hasil produksi suatu perusahaan. Promosi sebagai media untuk menjembatani kepentingan produsen dengan konsumen harus benar-benar dipahami oleh seorang manajer. Menurut Swastha (2006) mengatakan bahwa: "Promosi adalah arus informasi atau persuasi satu arah yang dibuat untuk mengarahkan seseorang atau organisasi kepada tindakan yang menciptakan pertukaran dalam pemasaran".

\section{Metode}

Penelitian ini termasuk jenis riset bersifat descriptive research yang bertujuan untuk menjelaskan hubungan-hubungan antara variable yang diteliti. Penelitian ini di kategorikan sebagai cross sectional (proses pengumpulan data dilakukan pada suatu waktu tertentu) yang akan dilakukan mulai dari bulan Mei 2018 untuk mendapatkan data yang diperlukan dalam penulisan tesis ini, peneliti mengadakan penelitian kepada pelanggan Garuda yang berlokasikan di Indonesia. 
Data primer adalah data yang dikumpulkan sendiri oleh peneliti dari obyek penelitian. Data primer yang dimaksud melalui kuisioner yang diberikan/disebarkan kepada pelanggan Garuda sebagai responden. Pengumpulan data sekunder relative lebih mudah, namun memiliki kelebihan dan kekurangan. Peneliti memperoleh data sekunder dari profil perusahaan PT. GARUDA, jurnal-jurnal, buku, internet dan bahan bacaan lainnya yang berkaitan dengan faktor-faktor yang akan diteliti.

Dalam penelitian ini, variable yang digunakan dan diklasifikasikan menjadi variable independen (variable bebas) yaitu kualitas pelayanan (x1), harga (x2) dan promosi (x3) dan variable dependen (variable tidak bebas) yaitu kepuasan pelanggan (y).

Untuk mengukur tanggapan responden terhadap variable-variabel penelitian digunakan skala likert karena adanya sejumlah pertanyaan sebagai alat untuk pengumpulan data atau informasi dari responden. Menurut Sekaran $(2003 ; 197)$, skala Likert didisain untuk menguji sampai sejauh mana tingkat kekuatan responden dari setuju sampai tidak setuju terhadap pernyataan tersebut dalam lima skala. Sugiyono (2004: 86) juga berpendapat bahwa salah satu cara yang paling sering digunakan dalam menentukan skor adalah menggunakan skala likert, yaitu pengukuran atas jawaban pernyataan-pernyataan yang dilambangkan dari skala: 5 (sangat puas); 4 (puas); 3 (netral); 2 (tidak puas); sampai dengan 1 (sangat tidak puas).

\section{A. Hipotesis Statistik dan Pengujiannya}

Uji Validitas, Koefisien validitas menggambarkan tingkat kemampuan instrumen untuk mengungkap data atau informasi dari variabel yang diukur. Teknik pengujian validitas menggunakan teknik korelasi product moment dari pearson dengan tingkat signifikansi 5\% untuk menge-tahui keeratan pengaruh antara variabel bebas dengan variabel terikat dengan cara mengkorelasikan antara skor item pernyataan terhadap skor total. Apabila nilai total pearson correlation > 0,3, atau probabilitas kurang dari 0,05 maka item tersebut valid (Arikunto,2002:146).

Uji Reabilitas, adalah tingkat kemampuan suatu instrumen penelitian untuk dapat mengukur suatu variabel secara berulangkali dan mampu menghasilkan informasi atau data yang sama atau sedikit sekali bervariasi. Dengan kata lain instrumen tersebut mampu menunjukkan keakuratan, kestabilan dan konsistensi dalam menghasilkan data dari variabel yang diukur(Arikunto,2002:171). Teknik pengujian reliabilitas menggunakan koefisien alpha cronbach dengan taraf nyata 5\%, Jika koefisien korelasi lebih besar dari nilai kritis atau jika nilai alpha cronbach lebih besar daripada 0,6 maka item tersebut dinyatakan reliabel. Koefisien alpha kurang dari 0,6 menunjukkan reliabilitas yang buruk, angka sekitar 0,7 menunjukkan reliabilitas dapat diterima dan angka di atas 0,8 menunjukkan reliabilitas yang baik. (Sekaran 2003:311)

Uji Asumsi Klasik, Pengajian asumsi klasik dilakukan untuk membuktikan apakah model regresi yang diujikan dalam penelitian baik atau layak digunakan. Dalam uji asumsi klasik terdapat tiga jenis pengujian yang akan dilakukan terhadap data yang akan dianalisis yaitu Uji Normalitas, Multikolinearitas, dan heteroskedastisitas. Ketiga pengujian asumsi klasik tersebut harus memenuhi persyaratan agar model regresi dinyatakan baik atau layak

Uji Normalitas, bertujuan untuk menguji apakah dalam suatu model regresi, error atau residualnya terdistribusi normal atau tidak. Model regresi yang baik seharusnya distribusi dari error atau residualnya normal atau mendekati normal.Untuk mendeteksi ada atau tidaknya 
normalitas, dapat dilakukan dengan menggunakan perangkat lunak program SPSS. Deteksi dengan melihat penyebaran data(titik) pada sumbu diagonal dari grafik normal probability plot. Dasar pengambilan keputusan (Santoso, 2001)

Uji Multikolinearitas, digunakan untuk mengetahui ada atau tidaknya penyimpangan asumsi klasik multikolinieritas, yaitu adanya hubungan linear antar variable bebas dalam model regresi (Priyanto,2011). Metode pengujian yang bisa digunakan yaitu dengan melihat nilai variance inflastion factor (VIF) dan tolerance pada model regresi. Jika nilai VIF kurang dari 10 dan tolerance lebih dari 0,1 maka model regresi bebas dari Multikolinieritas (Priyatno,2011).

Uji Heteroskedastisitas, dilakukan untuk mengetahui apakah dalam sebuah model regresi terdapat ketidaksamaan varian dari residual satu pengamatan ke pengamatan lain. Metode uji heteroskedastisitas bisa dianalisis menggunakan korelasi Spearman's rho yaitu mengkorelasikan variable independen dengan nilai unstandardized residual. Pengujian menggunakan tingkat signifikansi 0,005 dengan uj 2 sisi. Jika korelasi antara variable independen dengan residual didapat signifikansi lebih dari 0,05 maka dapat dikatakan bahwa tidak terjadi maslaah heterskedastisitas pada model regresi.

\section{B. Uji Hipotesis}

Uji t, Terdapat 4 buah hipotesis yang dijui dalam penelitian ini. Hipotesis pertama sampai dengan hipotesis keempat, menguji secara parsial pengaruh variabel terhadap kepuasan pelanggan. Dasar pengambilan keputusan dalam pengujian hipotesis ini dilakukan dengan membandingkan nilai $\mathrm{t}$ hitung dengan nilai $\mathrm{t}$ tabel dengan kriteria sebagai berikut: Bila $\mathrm{t}$ hitung > t tabel, maka Ha diterima dan Ho ditolak. Bila $t$ hitung $<\mathrm{t}$ tabel, maka Ha ditolak dan Ho diterima. Angka $t$ tabel dalam penelitian ini ditentukan, kemudian dilakukan dengan menghitung besarnya nilai degree of freedom) dan taraf signifikansi alfa $=5 \%$

Uji F, dimaksudkan untuk menguji variabel secara simultan atau bersama sama terhadap kepuasan pelanggan. Dasar pengambilan keputusan dilakukan dengan membandingkan antara besarnya nilai $\mathrm{F}$ hitung dengan $\mathrm{F}$ tabel dengan kriteria sebagai berikut: Bila $\mathrm{F}$ hitung > Ftabel, maka Ha diterima dan Ho ditolak; Bila F hitung < Ftabel, maka Ha ditolak dan Ho diterima.

Uji Koefisien Determinasi, Menurut Widyasari, 2009 Koefisien determinasi pada intinya mengukur seberapa besar kemampuan variabel bebas (X) dalam menerangkan variasi perubahan pada variabel terikat (Y). Hasil pengolahan data dengan menggunakan regresi linier berganda menunjukkan bahwa besarnya angka koefisien determinasi (adjusted $R$ Square)Koefisien Determinasi mengukur seberapa besar penyimpangan variable dependen terhadap nilai tengahnya yang dijelaskan oleh variable independen. Nilai koefisien determinasi dapat bervariasi antara 0 dan 1 (Hair, 2010). Analisis ini dilakukan untuk mengetahui seberapa jauh variabel independen dapat menjelaskan perubahan variabel dependen. Nilai persentase $\mathrm{R}^{2}$ menunjukkan seberapa besar variabel dependen dapat dijelaskan oleh variabel independen, dan sisanya $\left(1-\mathrm{R}^{2}\right)$ dijelaskan oleh variabel lain yang tidak termmasuk dalam mmodel regresi ini

\section{Hasil}

Jumlah total kuesioner yang telah dilengkapi dan valid untuk diolah dan dianalisis adalah berjumlah 166 kuesioner. Kuesioner dalam bentuk digital dengan menggunakan 
Google Form.Jawaban yang telah diberikan sudah merupakan data kuantitatif sesuai dengan bobot yang telat ditentukan. Kemudian data mentah diolah dengan bantuan software SPSS ver 20. Berikut ini diungkapkan deskripsi responden sebagai latar belakang informasi sample penelitian ini. Penulis menganalisis kuesioner dari 166 responden dengan 7 pertanyaan mengenai identitas dirinya, yaitu jenis kelamin, usia, pendidikan terakhir, pekerjaan, domisili, besaran pengeluaran tiap bulan danjumlah menggunakan maskapai Garuda Indonesias. Identitas ini bertujuan untuk mengetahui statistik atau deskripsi responden dalam penelitian ini.

\section{A. Uji Validitas dan Reliabilitas}

Tabel 1. Uji Validitas

\begin{tabular}{|c|c|c|c|c|}
\hline Variabel & Item & r hitung & $r$ tabel & Keputusan \\
\hline \multirow{15}{*}{$\begin{array}{l}\text { Kualitas } \\
\text { Pelayanan } \\
\quad \text { (X1) }\end{array}$} & Item 1 &, 549 &, 1524 & valid \\
\hline & Item 2 & ,425 &, 1524 & valid \\
\hline & Item 3 & ,404 &, 1524 & valid \\
\hline & Item 4 &, 345 &, 1524 & valid \\
\hline & Item 5 & ,445 &, 1524 & valid \\
\hline & Item 6 & ,567 &, 1524 & valid \\
\hline & Item 7 & ,436 &, 1524 & valid \\
\hline & Item 8 & ,417 &, 1524 & valid \\
\hline & Item 9 & ,470 &, 1524 & valid \\
\hline & Item 10 & ,443 &, 1524 & valid \\
\hline & Item 11 &, 581 &, 1524 & valid \\
\hline & Item 12 &, 540 &, 1524 & valid \\
\hline & Item 13 &, 589 &, 1524 & valid \\
\hline & Item 14 &, 515 &, 1524 & valid \\
\hline & Item 15 & ,685 &, 1524 & valid \\
\hline \multirow{3}{*}{ Harga (X2) } & Item 1 & ,583 &, 1524 & valid \\
\hline & Item 2 & ,643 &, 1524 & valid \\
\hline & Item 3 & ,894 &, 1524 & valid \\
\hline \multirow{3}{*}{ Promosi (X3) } & Item 1 & ,627 &, 1524 & valid \\
\hline & Item 2 & ,647 &, 1524 & valid \\
\hline & Item 3 & ,861 &, 1524 & valid \\
\hline
\end{tabular}




\begin{tabular}{|c|c|c|c|c|} 
& \multicolumn{3}{|c|}{} \\
\hline \multirow{4}{*}{$\begin{array}{c}\text { Kepuasan } \\
\text { Pelanggan } \\
(Y)\end{array}$} & Item 1 &, 743 &, 1524 & valid \\
\cline { 2 - 5 } & Item 2 &, 648 &, 1524 & valid \\
\cline { 2 - 5 } & Item 3 &, 580 &, 1524 & valid \\
\cline { 2 - 5 } & Item 4 &, 903 &, 1524 & valid \\
\hline
\end{tabular}

Berdasarkan Tabel 1 di atas, terlihat bahwa $r$ hitung lebih besar dari $r$ tabel $(0,1524)$, maka dapat disimpulkan bahwa item - item dalam kuesioner yang disebarkan valid.

Tabel 2. Uji Reliabilitas

\begin{tabular}{|c|c|c|c|}
\hline Variabel & Alpha & Batas r & Keputusan \\
\hline $\begin{array}{c}\text { Kualitas Pelayanan } \\
(\mathrm{X} 1)\end{array}$ &, 944 & 0,700 & Reliabel \\
\hline Harga (X2) &, 794 & 0,700 & Reliabel \\
\hline Promosi (X3) &, 853 & 0,700 & Reliabel \\
\hline $\begin{array}{c}\text { Kepuasan Pelanggan } \\
\text { (Y) }\end{array}$ &, 820 & 0,700 & Reliabel \\
\hline
\end{tabular}

Berdasarkan Tabel 2 di atas, terlihat bahwa nilai Croanbach's alpha untuk seluruh variabel bernilai di atas 0,7 dan dapat disimpulkan bahwa kuesioner yang disebarkan bersifat reliabel.

\section{B. Deskriptif Karakteristik Responden}

Deskripsi responden berdasarkan jenis kelamin tercatat bahwa responden penelitian ini lebih didominasi oleh responden dengan jenis kelamin pria (76\%). Sedangkan sisanya sebesar (90\%) adalah responsen penelitian dengan jenis kelamin wanita. Dengan demikian mayoritas responden adalah wanita dibandingkan pria. Dalam hal deskripsi atau profil responden berdasarkan usia jumlah responden yang berusia $<21$ tahun sebanyak 28 orang $(16,9 \%)$. Usia 21-25 tahun sebanyak 90 orang (54,2\%) usia 26-30 tahun sebanyak 34 orang (20,5\%), usia 31-35 tahun sebanyak 8 orang (4,8\%), usia 36-40 tahun sebanyak 3 orang (1,8\%), usia 41-45 tahun sebanyak 3 orang $(1,8 \%)$. Dengan demikian mayoritas responden berusia 21-25 tahun sebanyak 90 orang $(54,2 \%)$ dari keseluruhan responden. Berdasarkan tingkat pendidikan bahwa responden yang memiliki tingkat pendidikan terakhir dijenjang SMA atau lebih rendah sebanyak 54 orang $(32,5 \%)$, kemudian diikuit dengan tingkat pendidikan Diploma sebanyak 7 orang (4,2\%), sedangkan tingkat pendidikan Sarjana sebanyak 99 orang $(59,6 \%)$, dan Magister sebanyak 5 orang (3\%) dan yang lainnya sebanyak 1 orang $(0,6 \%)$. Dari 166 responden yang diteliti, didapat bahwa responden terbesar adalah pelajar/mahasiswa sebanyak 39 orang $(23,5 \%)$ selanjutnya responden dengan profesi karyawan swasta yang terdiri dari 87 orang $(52,4 \%)$. Sedangkan responden dengan profesi pegawai negeri sebanyak 1 orang $(0,6 \%)$ untuk wiraswasta sebanyak 35 orang $(21,1 \%)$ dan yang lainnya sebanyak 4 orang $(2,4 \%)$. jumlah responden yang mempunyai pengeluaran perbulan kurang dari Rp.3.000.000 sebanyak 59 orang $(35,5 \%)$. Untuk responden yang mempunyai pengeluaran perbulan Rp. 3.000.000-Rp 4.000.000 sebanyak 36 orang (21,7\%). Untuk responden yang mempunyai pengeluaran perbulan $\mathrm{Rp} 4.000 .000$ - Rp 5.000.000 sebanyak 31 orang (18,7\%). Untuk responden yang mempunyai pengeluaran perbulan Rp 5.000.000 - Rp. 6.000 .000 sebanyak 11 orang $(6,6 \%)$. Dan untuk responden yang mempunyai pengeluaran lebih dari Rp. 6.000 .000 sebanyak 29 orang $(17,5 \%)$. 


\section{Hasil Analisis Data}

Salah satu cara untuk mendeteksi adanya multikolinieritas adalah dengan melihat tolerance atau varians inflation factor (VIF). Pada tabel 3 diberikan hasil uji multikolinieritas

Tabel 3. Uji Multikolinearitas

\begin{tabular}{|c|c|c|c|}
\hline \multirow{2}{*}{\multicolumn{2}{|c|}{ Model }} & \multicolumn{2}{|c|}{$\begin{array}{l}\text { Collinearity } \\
\text { Statistics }\end{array}$} \\
\hline & & $\begin{array}{c}\text { Toleranc } \\
\mathrm{e}\end{array}$ & VIF \\
\hline \multirow{4}{*}{1} & (Constant) & & \\
\hline & $\begin{array}{l}\text { x1_Kualitas_Pelaya } \\
\text { nan }\end{array}$ & ,979 & 1,021 \\
\hline & x2_Harga & 631 & 1,585 \\
\hline & x3_Promosi & ,633 & 1,580 \\
\hline
\end{tabular}

Adapun dasar pengambilan keputusan untuk uji multikolinieritas :Jika VIF $<10$; tolerance $>0,1$ maka tidak ada gejala multikolinieritas. Jika VIF $>10$ maka terjasdi gejala multikolinieritas. Melihat hasil pengolahan di atas, didapatkan nilai VIF lebih kecil dari 10, dengan demikian dapat disimpulkan bahwa model regresi yang digunakan dalam penelitian ini tidak memiliki gejala multikolinieritas.

\section{Analisis Regresi Ganda}

Hasil pengolahan regresi ganda menggunakan SPSS adalah sebagai berikut:

Tabel 4. Hasil Regresi Ganda

\section{Coefficients $^{\mathrm{a}}$}

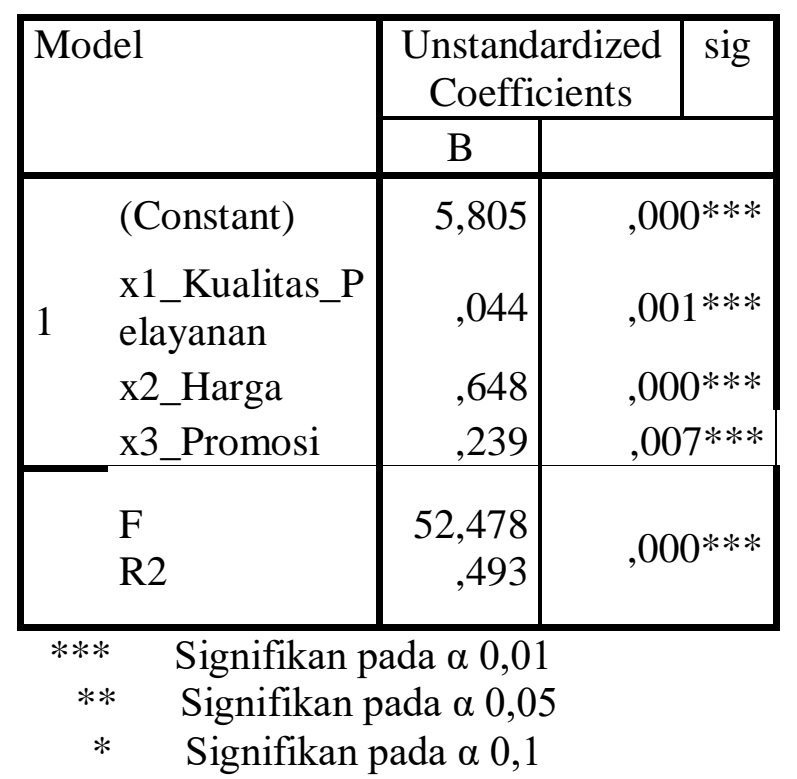

Pertama, jika kualitas pelayanan (X1), harga (X2), dan promosi (X3) sebesar nol, maka kepuasan pelanggan (Y) yakni sebesar 5.805. Kedua, jika terjadi perubahan x1 (kualitas 
pelayanan) sebesar 1 satuan, maka Y (kepuasan pelanggan) akan mengalami perubahan (kenaikan) sebesar 0.044 satuan. Ketiga, jika terjadi perubahan X2 (harga) sebesar 1 satuan, maka Y (kepuasan pelanggan) akan mengalami perubahan (kenaikan) sebesa 0.648 satuan. Keempatm jika terjadi perubahan X3 (promosi) sebesar 1 satuan, maka Y (kepuasan pelanggan) akan mengalami perubahan (kenaikan) sebesar 0.239 satuan. Selain itu, dari persamaan tersebut juga dapat diperhatikan bahwa nilai koefisien variabel yang terbesar adalah nilai koefisien dari variabel kualitas pelayanan, kemudian diikuti oleh nilai koefisien variabel harga dan terakhir adalah koefisien dari variabel promosi.

\section{Kesimpulan}

1. Hasil uji hipotesis keempat menyatakan bahwa variabel kualitas pelayanan, harga, dan promosi secara bersama-sama memiliki pengaruh yang signifikan terhadap kepuasan pelanggan.

2. Didapatkan bahwa variabel kualitas layanan, harga dan promosi mempunyai kontribusi atau kemampuan menjelaskan varians dari variabel keputusan pembelian sebesar 48,3\% sedangkan untuk sisanya sebesar 51,7\% dijelaskan oleh variabel lain yang tidak diteliti di sini.

\section{DAFTAR PUSTAKA}

Basu Swastha dan Irawan, 2006, Manajemen Pemasaran Modern, Liberty, Yogyakarta Kotler, P. \& Amstrong, G. (2001). Dasar-dasar Pemasaran Edisi IX. Jakarta: PT.Indeks. Kotler, Plilip. 2000. Manajemen Pemasaran. Edisi Mileinium. Jakarta : PT. Indeks Kelompok Gramedia.

Pelayanan pada Rumah Sakit Umum Kabupaten Karang Anyer.Jakarta. Skripsi

Sekaran, Uma. (2003). Metodologi Penelitian Untuk Bisnis. Jakarta: Salemba 4. (2006). Metodologi Penelitian Untuk Bisnis. Jakarta: Salemba 4.

Sugiyono. 2004. Metode Penelitian. Bandung: Alfabeta.

Tse dan Wilton (1988). Kepuasan Pelanggan, jilid 2. Edisi ketiga. Klaten : PT. Indeks Kelompok Gramedia.

Tjiptono, Fandy.1997. Strategi Pemasaran. Yogyakarta: bayumedia publishing. Wahyuningsih, Anis. 2002. Analisa Tingkat Kepuasan Konsumen Berdasarkan Kualitas Fakultas Ekonomi Program Studi Manajemen UMS. 


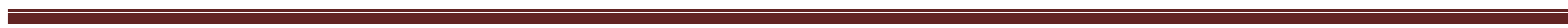
$\cdot$ 